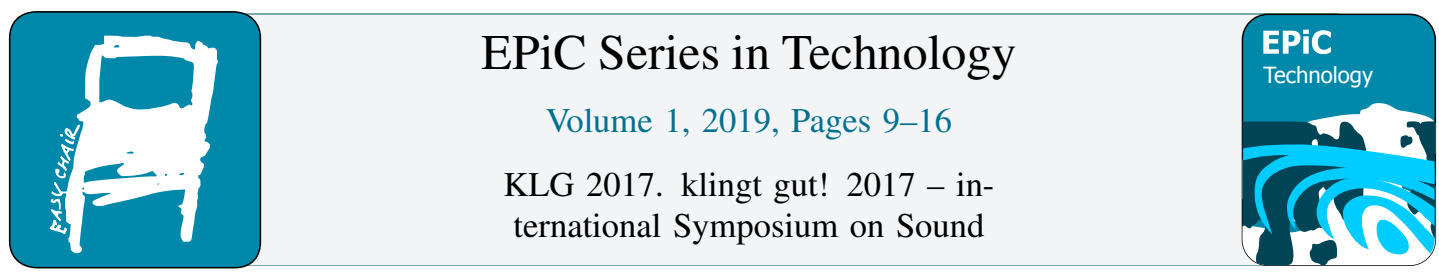

\title{
Virtual Acoustics for Concert Advertisement
}

\author{
Johann-Markus Batke \\ Hochschule Emden/Leer \\ Johann-Markus. Batke@hs-emden-leer. de
}

\begin{abstract}
"Vision Kirchenmusik" is a project group aiming to find new concepts for presenting church music to the public. One of the most recent projects was the concert advertisement announcing the St. Luke Passion composed by Krzystof Penderecki. This contribution reports on the audio production carried out for this project focussing on a guided inner city walk containing light art and sound installations. In particular, the binaural synthesis and use of reverb for Higher Order Ambisonics rendering is discussed.
\end{abstract}

\section{Introduction}

"Vision Kirchenmusik" is a project group driven by the Evangelisch-lutherische Landeskirche Hannover [1]. Besides networking activities and educative tasks the project researches on new concepts for presenting church music to the public. This includes the organisation of events and concerts using contemporary approaches as well as innovative ways in music communication. Of course also traditional ways like informative talks or themed church services are organised by "Vision Kirchenmusik".

In this contribution we look at their project "Passio 2017". This project was launched due to the "Reformationsjahr" celebrations to perform the St. Luke Passion composed by Krzystof Penderecki [2].

The St. Luke Passion concert performances took place in three cities, i.e. Hannover, Lüneburg, and Emden. In this contribution we solely focus on the concert advertisement that took place in Emden. The advertisement was prominently realised by a guided inner city walk containing sound installations and binaurally enhanced audio excerpts.

In section 2 we shortly introduce the music of the St. Passion by Krzysztof Penderecki. Then some more background on the inner city walk is given. The playback technology is described in section 3 .

\section{Project}

Krzysztof Penderecki is a Polish composer and conductor born in Dębica in 1933. The St. Luke Passion ("Passio et mors Domini nostri Jesu Christi secundum Lucam") belongs to his best known works. It is written in an avant-guarde musical language. The orchestration is scored for a large ensemble with narrator, soprano, baritone and bass soloists, three mixed choruses and a boys' choir, as well as a large orchestra. The St. Luke Passion premiered on 30 March 1966 in Münster Cathedral, whose immense success brought genuine popularity to the then 32 -year-old composer [3]. 


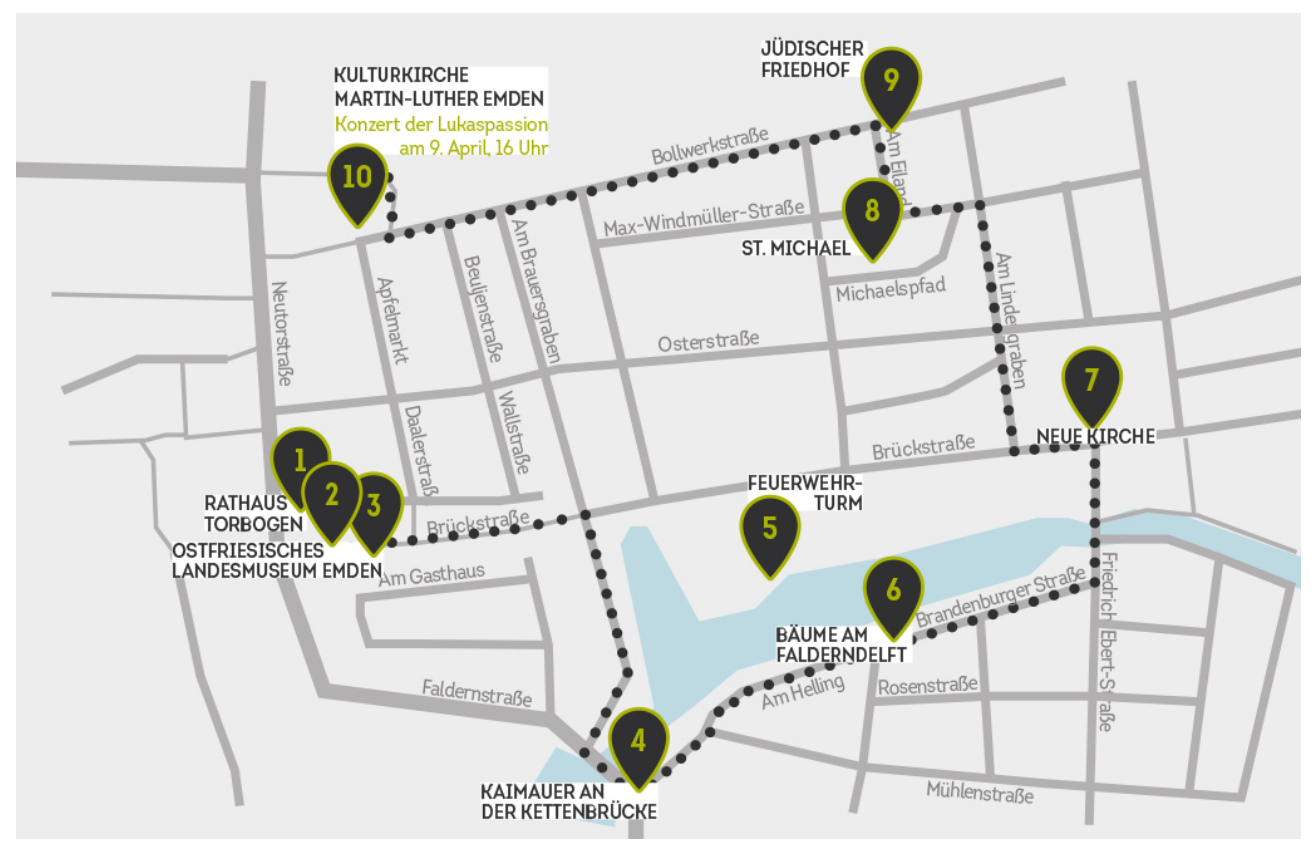

Figure 1: This map shows all stations of the guided walk through the inner city of Emden. [2]

The music of Penderecki's St. Luke Passion is highly complex, it is demanding for the performing musician and also for the listener. Moreover the genre of Penderecki's composition is often not expected being church music. The need for special action to make a concert performance of the St. Luke passion successful was very obvious. "Vision Kirchenmusik" took this challenge and implemented various activities in Hannover, Lüneburg and Emden. The inner city walk in Emden was therefore intended to prepare peoples' expectations and general understanding of the music of Krzysztof Penderecki.

\subsection{Inner City walk}

The inner city walk was besides information events, school projects and themed church services the essential part of the concept developed by "Vision Kirchenmusik" in Emden. It provided a number of installations with light art, music, prose and other information reflecting the music of the St. Luke's passion. Therefore the walk was also referred to as "Light and Sound Parcours".

There were ten stations in total, the main component of each station was some light art. Figure 1 shows the map with all stations of the walk.

Three stations had loudspeaker installations playing back music excerpts of the St. Luke passion during the evening hours. Additionally, the music and other content was provided online for mobile consumption (i.e. using a smart phone). The resources were made accessible by CR codes as shown in Figure 2.

\subsection{Light art}

The light art was created by Nikola Dicke for this project. [4]. At the 10 parcours stations the light art was realised by various projections onto walls of buildings, the ground or other surfaces. The content 


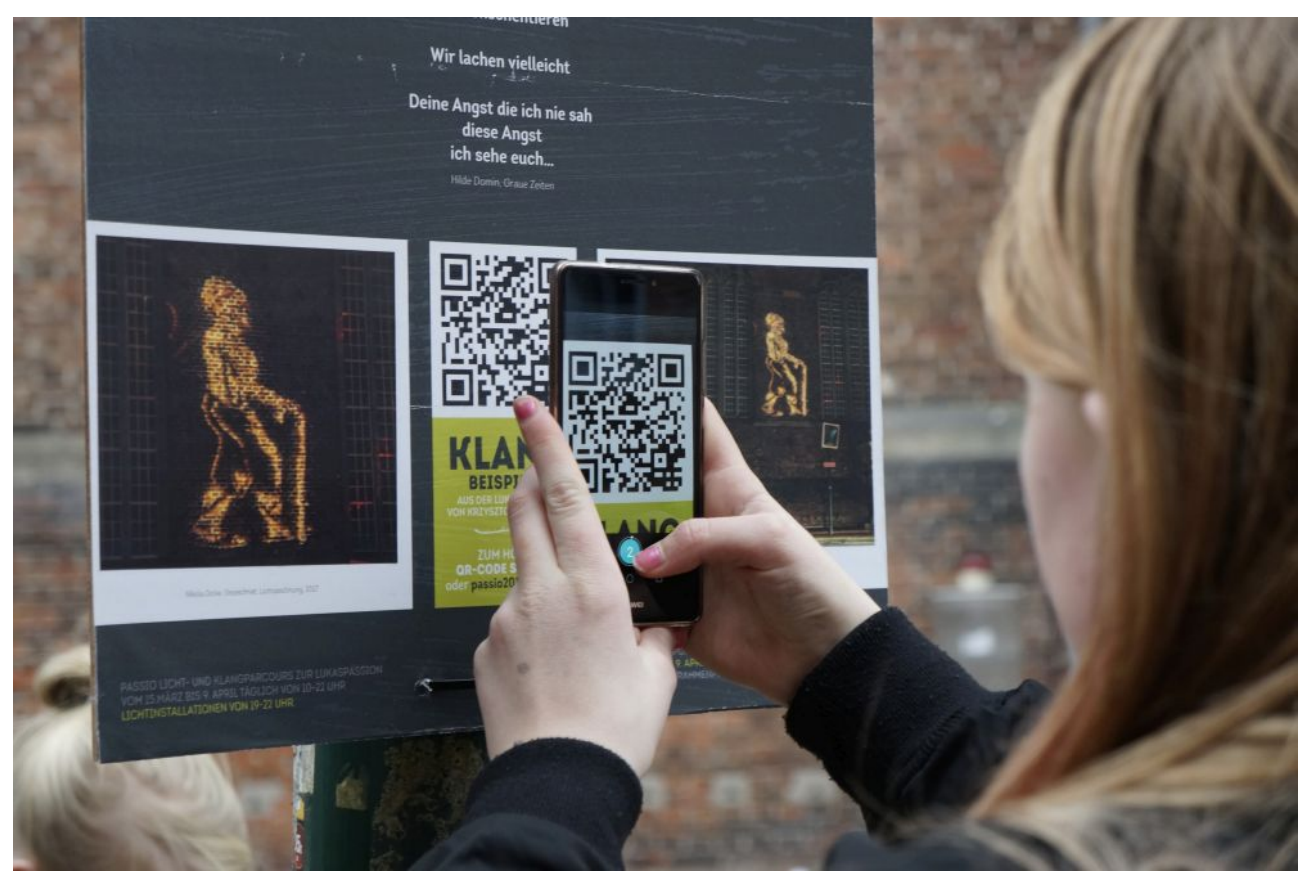

Figure 2: QR-Codes are found at the stations of the inner city walk to provide access to the music and additional content. [2]

reflects the musical material, the visual impression was intended to guide the viewer's emotions. A selection of three images is given here, a complete summary is found in Rolf [2].

Figure 3 shows an image of an animated drawing by Nikola Dicke of refugees, combined with a movie with refugees in world war II. Both were projected on the walls of the Luther-Kirche. At this station (\#10 of the parcours) sound was provided via a loudspeaker positioned outside in front of the church.

The projection "Entäuschung" referring the St. Luke passion shown in Figure 4 was slowly moving on the surface of the the ceiling inside the church St. Michael (\#8 of the parcours). The spectator was only able to enter the hallway of the church and had to look through a glass door. Inside the church a Penderecki music excerpt was played back via a loudspeaker. However, no direct sound from the loudspeaker was reaching the spectator. Instead, much reverb due to the church's acoustics caused strong low pass characteristics of the resulting sound in the hallway. Normally this is undesirable for public address systems, but in the context of this specific situation it was greatly serving the artistic intend.

Not only walls, but also tree trunks were used for the projection of images as shown in Figure 5. As for most other other stations, the music was provided online only at this station.

\subsection{On-line music presentation}

The music presented on-line was supposed to be listened to using head phones. Accordingly the option of binaural synthesis facitilitated an adaption of the music excerpts to the individual stations of the walk.

The resulting binauralisation of the online examples should match to the content of each station acustically. This could be achieved by reflecting the light art presentation. A presentation in a reverber- 


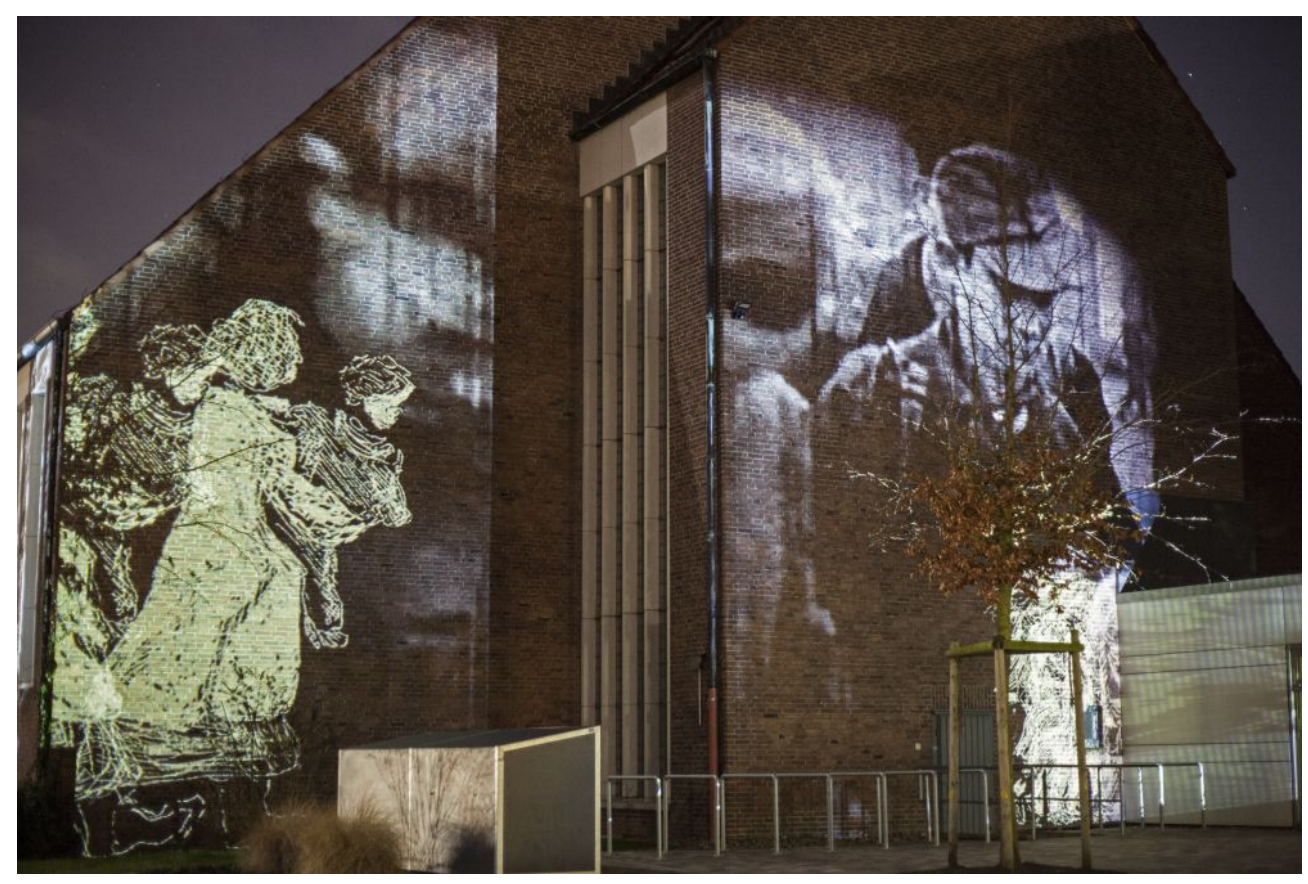

Figure 3: "Weltspuren" - light art animation sequence by Nikola Dicke combined with a movie; LutherKirche Emden (station 10)

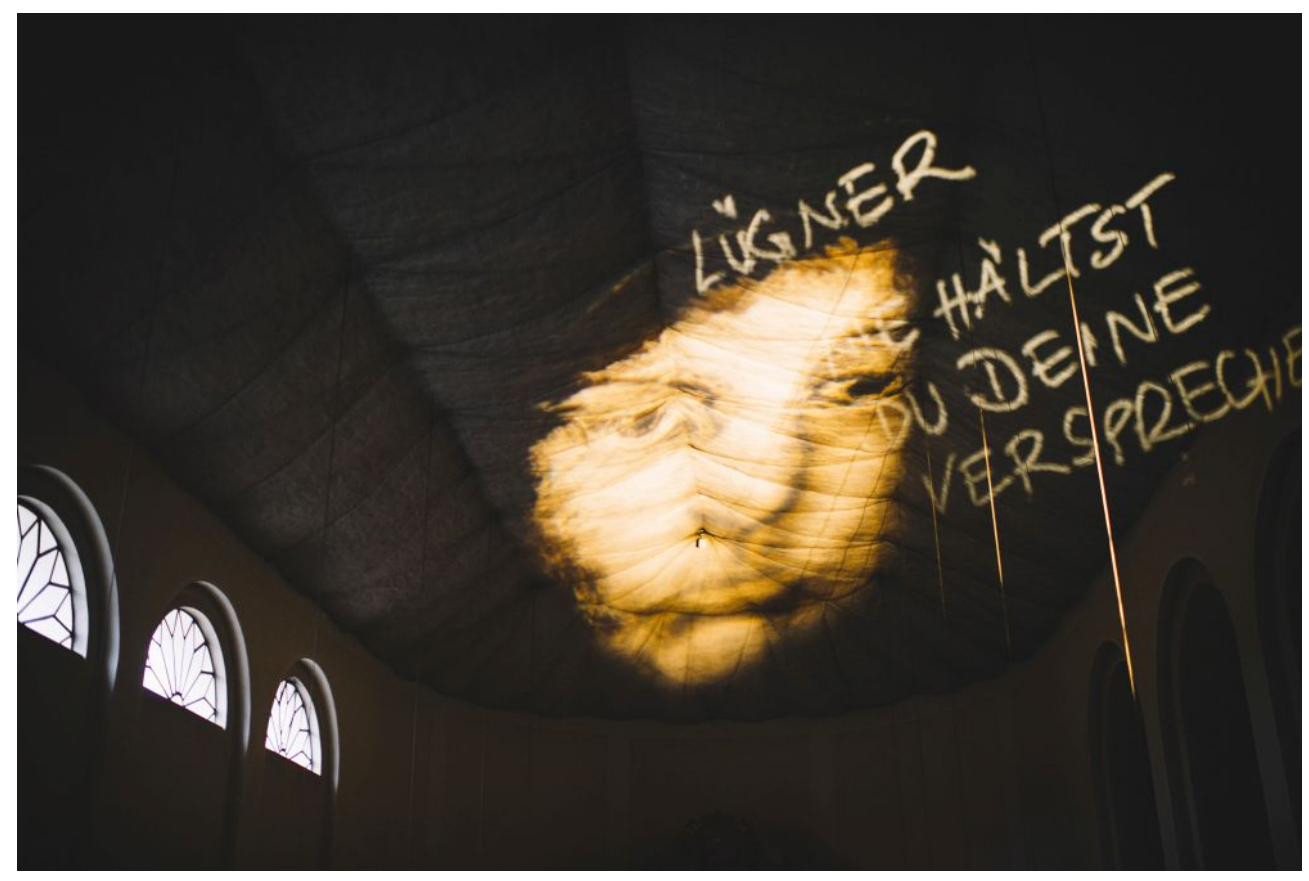

Figure 4: "Enttäuschung" shows the projection of a drawing by Nikola Dicke on the ceiling inside the church St. Michael (station 8). 


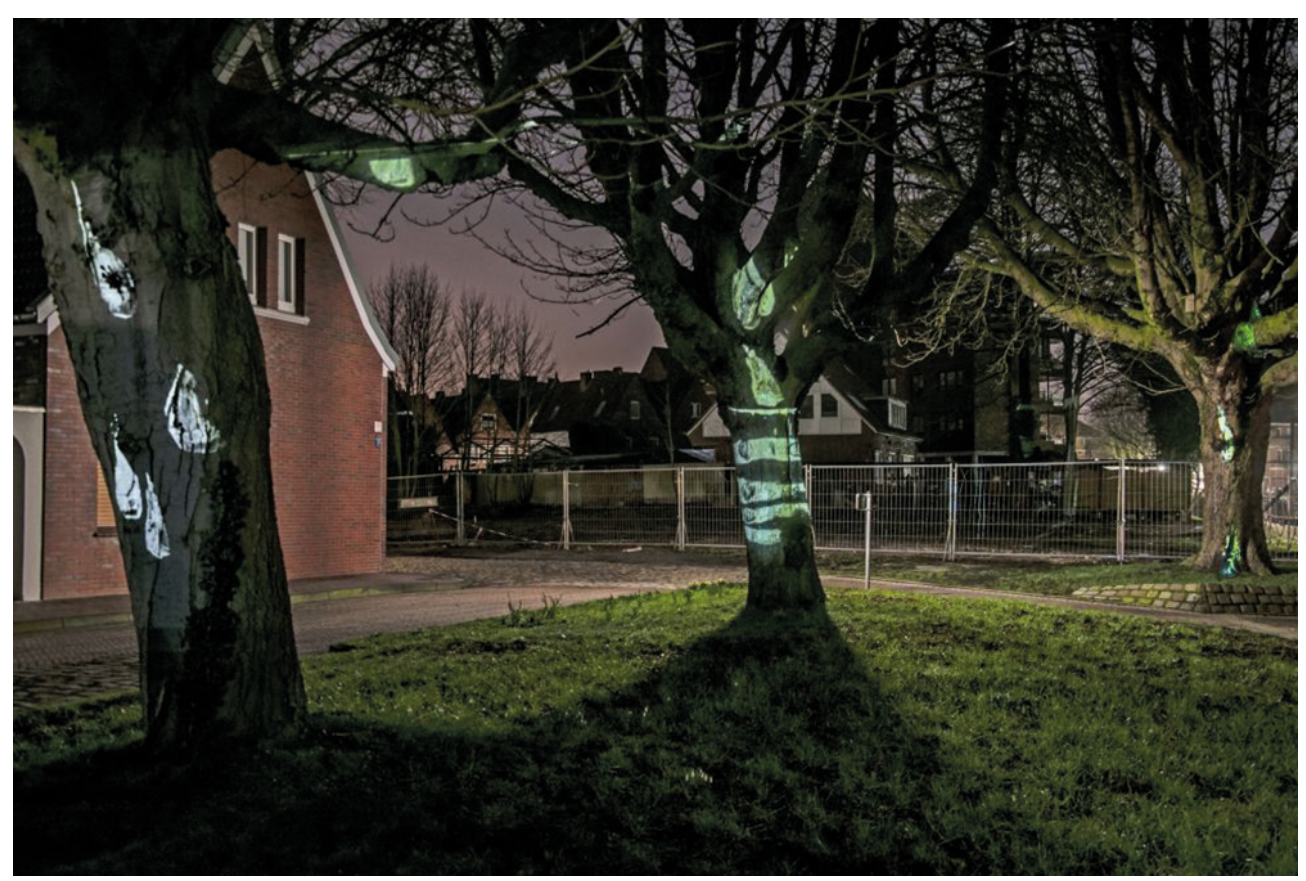

Figure 5: "Tränen" are animated tears flowing down trees (station 6).

ant environment may demand some reverb on the acoustical side. A presentation in free field conditions might suggest a very dry auralisation of the musical content.

On the other side, the content of the St. Luke passion itself could motivate certain acoustic details. Jesus in front of King Herod could have happened inside and needs reverb, in opposite to the crucifixion that happened outside.

Finally the emotional impact of a virtual acoustic environment has to be considered. A dry and analytical presentation of music evokes other emotions than the same piece of music in a bombastic reverberant hall. Considering all these aspects helps to find the right decision for a proper binauralisation. The technical options to accomplish the binauralisation are described in the the following section.

\section{Playback technology}

The use of head phones enables the application of virtual acoustics. Binaural synthesis is used for the rendering of virtual sources [5]. The music of the St. Luke Passion is provided as a stereo CD recording. The stereo signal can be played back using a pair of virtual loudspeakers when using binaural synthesis. This kind of playback avoids the effect of "in head" localisation normally occurring for head phone listening. On the other side, the effect of "in head" localisation can be employed as an artistic mean.

Head related transfer functions (HRTF) are required for binaural playback [5], [6]. The problem of HRTF individualisation largely affects the qualtity of experience. In the context of the "Passio 2017" project individualisation of HRTF was technically not reasonable. Instead, two different tool kits used for binauralisation were taken and applied as found appropriate to the content.

The spatialisation of signals is accomplished using Higher Order Ambisonics (HOA). This is described in more detail in Section 3.1. After that Section 3.2 discusses spatial aspects of reverb in partic- 


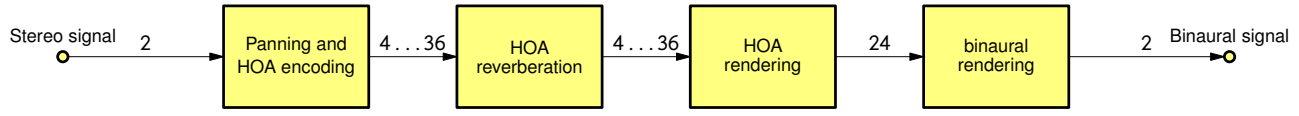

Figure 6: The HOA based processing chain employed for the binauralisation of the stereo recordings. The processing blocks are implemented using the toolkits Ambix, MCFX, and ATK [7]-[9].

ular.

\subsection{Processing Chain}

Figure 6 surveys the general processing chain for binaural signal generation:

1. The stereo signal is fed to a HOA panning tool in the beginning. This panning tool positions the left and right speaker signal in space, i.e. usually yielding a opening angle of $60^{\circ}$. The encoding to HOA coefficients results in a 4 to 36 channel representation depending on HOA order $N$.

2. The next step in the processing chain is to add audio effects like reverberation. In that case, the HOA signal is convolved with a HOA representation of a room impulse response. By this step addtional $3 \mathrm{D}$ information is added to the stereo scene.

3. The output of the effect section is rendered to specific loudspeaker positions. In our case most audio examples were processed to 12 positions in space yielding a 3D loudspeaker installation.

4. To obtain a binaural synthesis of the 3D soundfield as created by the 12 loudspeaker layout of the recent step, all loudspeaker signals are convolved with a set of head related transfer functions. The result is a binauralisation of the $3 \mathrm{D}$ soundfield.

To implement this processing chain in a digital audio workstation (DAW), a number tool-kits was employed. As a OSX based platform was used, the selected DAW is Reaper (V5.40, [10]). The toolkits used in this work are Ambix beeing a "Ambisonic plugin suite" [7], the "multichannel audio plug-in suite" (MCFX) [8], and the "Ambisonic Toolkit" (ATK) [9], [11].

The tool-kits are used in three different setups. The first setup directly reflects the processing chain as shown in Figure 6. The panning and encoding stage is implemented using ambix encoder i2 $\circ 1$. The plugin takes the two input channels and allows steering of the two directions being encoded. The HOA output is set to order $N=1$. The subsequent reverb processing by the mcfx convolver $\circ 1$ determines this order as the HOA impulse responses provided by the MCFX package are first order. Finally, the last two stages are implemented by the ambix binaural ol plugin using the iem_cube_h2_allrad-01 setup.

The second setup omits the reverb processing, therefore the order is no longer limited and was chosen to $N=5$ to emphazise the spatial resolution.

The third setup employs the ATK. The ATK only supports First Order Ambisonics (FOA), e.g. $N=1$. For the encoding stage the ATK FOA Encode SuperStereo is used. "Super Stereo" is often used in the context of UHJ Ambisonics representations [12], claiming to yield a wider stereo image than produced with conventional methods. The decoding and binaural rendering is again jointly processed in a single plugin called ATK FOA Decode Binaural. The ATK provides a variety of head related transfer functions that can be selected for binaural rendering. 


\subsection{Reverb}

The perception of envelopment when listening to a multi channel loudspeaker presentation is caused by the spatial information of the recording and in particular by the reverberation contained in the recording. Also, some reverb is caused by the listening environment that also envelopes the listener. While 3D and surround loudspeaker layouts naturally can provide a rich amount of envelopment, this is more limited for stereo playback.

The envelopment caused by the binaural synthesis of stereo content is mainly due to reverb in the content and reverberation information contained in the HRTF set used for binauralisation. Often it is desired to have a dry HRTF set to enable the playback of binaural content "as is" without any additional reverb from the virtual playback room. On the other side, for virtual loudspeaker representations of real loudspeaker setups like stereo or surround sound the presence of reverb appears to be useful.

Binaural synthesis provides virtual sources for all directions around the listener. Therefore the envelopment can be enhanced by additional reverb that is spatially spread to all directions around the listener's head. In other words, additionally to the virtual stereo pair of loudspeakers reverb sources are added for better envelopment.

The reverb properties in general depend on the early reflections and diffuse part (or reverb tail). Naturally, the early reflections carry information about the acoustical environment that is auralised by the reverberations. However, for a natural perception of reverb, the reverb tail may also contribute to spatial information of the sound field and therefore needs careful treatment [13].

In this contribution, the spatial reverb added to the stereophonic content of the $\mathrm{CD}$ production is generated by means of First Order Ambisonics (FOA). B-Format recordings are provided with the MCFX toolbox [8].

\section{Discussion and outlook}

The project group "Vision Kirchenmusik" advertised concerts presenting the St. Luke passion by Krzysztof Penderecki organising the project "Passio 2017". In Emden an inner city walk with ten stations presented light art combined with audio examples being binaurally processed to fit to the content of the individual stations. Since all concerts were sold out the project can be denoted being successful overall.

The binaural processing using Higher Order Ambisonics was described on basis of the tool kits employed, in particular AMBIX and ATK. The use of these tool kits enables are variety of creative options to tailor the playback accordingly to the individual stations of the walk. On the other side the impact of the binauralisation cannot be precisely specified. Due to the lack of the individual HRTF the effect of binauralisation might have been weak. As only processed playback was presented to the listener, no comparison to unprocessed audio content is possible.

\section{References}

[1] U. Pankoke. (2017). Vision kirchenmusik, Damit dein funke überspringt, Ev.-luth. Landeskirche Hannovers, [Online]. Available: http://www.visionkirchenmusik.de.

[2] H.-J. Rolf. (2017). Passio penderecki 2017, Passio et mors domini nostri iesu christi secundum lucam, [Online]. Available: passio2017. de (visited on 07/15/2017).

[3] A. Gusowski. (2017). St. pauls cathedral, münster / st. luke's passion by krzysztof penderecki, Porta Polonica - Westfälisches Landesmuseum für Industriekultur, [Online]. Available: http : / / www . porta-polonica.de (visited on 07/06/2017).

[4] N. Dicke. (2017). Raum licht zeichnung, [Online]. Available: www . nikoladicke.de. 
[5] B. Xie, Head-related transfer function and virtual auditory display. J. Ross Publishing, 2013.

[6] J. Blauert, Ed., Communication Acoustics, 2005.

[7] M. Kronlachner. (2014). Ambix v0.2.7 - ambisonic plug-in suite, [Online]. Available: http: / / www . matthiaskronlachner. com/ ?p=2015 (visited on 07/06/2017).

[8] —, (2014). Mcfx v0.5.2 - multichannel audio plug-in suite, [Online]. Available: http : / / www. matthiaskronlachner. com/?p=1910 (visited on 07/06/2017).

[9] ATK Community. (2016). The ambisonic toolkit, Tools for soundfield-kernel composition, [Online]. Available: http: / / www . ambisonictoolkit. net/ (visited on 07/06/2017).

[10] Cockos INC. (2017). Reaper, Audio production without limits, [Online]. Available: http: // www. reaper. fm/ (visited on 07/06/2017).

[11] T. Lossius and J. Anderson, "Atk reaper: The ambisonic toolkit as jsfx plugins", in Proceedings ICMCI SMCI 2014, (Athens, Greece, Sep. 14, 2014), 2014.

[12] F. Stevens, D. Murphy, and S. Smith, "Ecological validity of stereo uhj soundscape reproduction", in Audio Engineering Society Convention 142, May 2017. [Online]. Available: http: / / www . aes.org/e-lib/browse. cfm?elib=18641.

[13] G. von Schultzendorff, R. Höpfner, and J.-M. Batke, "Real-diffuse enveloping sound reproduction", in ICSA 2015, 3rd International Conference on Spatial Audio, Graz, 2015. 